\title{
Colonic Amyloidosis Concomitant with Systemic Lupus Erythematosus
}

\author{
Kozo Ikuta ${ }^{1}$, Saori Hatachi ${ }^{2}$, Takahiro Fujimori ${ }^{3}$ and Seiji Shio ${ }^{1}$
}

Key words: systemic lupus erythematosus, amyloidosis

(Intern Med 59: 2799-2800, 2020)

(DOI: 10.2169/internalmedicine.5109-20)

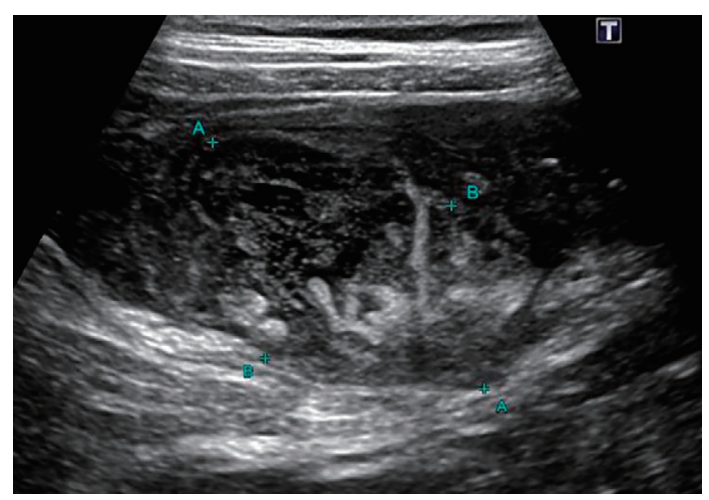

Picture 1.

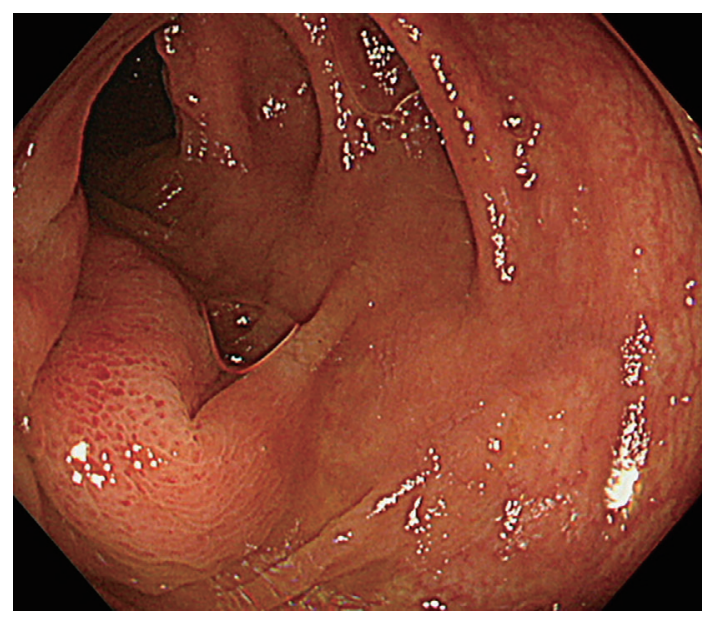

Picture 3.

A 43-year-old woman with a 20-year history of systemic lupus erythematosus (SLE) complained of lower abdominal pain and a high fever. We and her previous physicians had controlled the disease activity of SLE well using predniso-

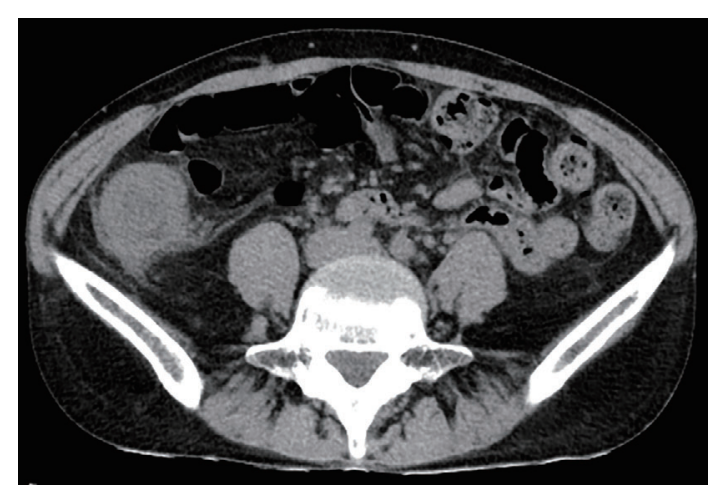

Picture 2.

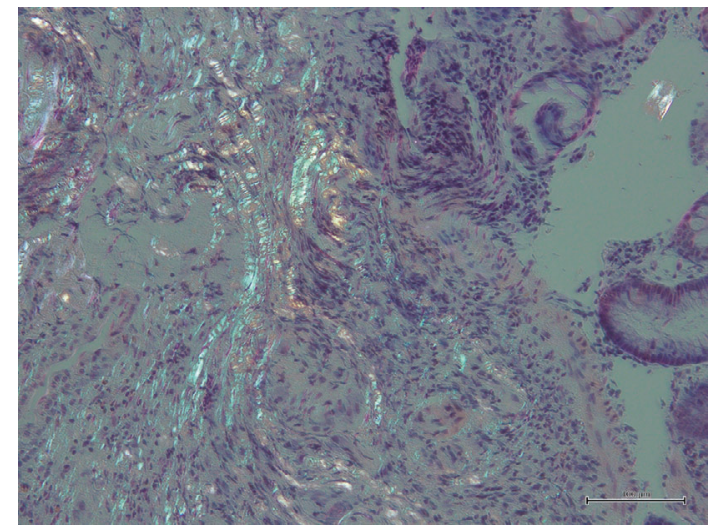

Picture 4.

lone, tacrolimus, hydroxychloroquine and mycophenolate mofetil for a number of years. Abdominal ultrasonography and computed tomography (CT) showed swelling of the ascending colonic wall (Picture 1, 2). Colonoscopy showed mucosal swelling and small red spots in the ascending colon (Picture 3). Congo red staining using the biopsy specimens

${ }^{1}$ Division of Gastroenterology, Shinko Memorial Hospital, Japan, ${ }^{2}$ The Center for Rheumatic Diseases, Shinko Memorial Hospital, Japan and ${ }^{3}$ Department of Pathology, Shinko Memorial Hospital, Japan

Received: April 20, 2020; Accepted: May 25, 2020; Advance Publication by J-STAGE: July 14, 2020

Correspondence to Dr. Kozo Ikuta, kikuta@kuhp.kyoto-u.ac.jp 
from the swollen mucosa was positive for amyloid deposition, and green birefringence was observed under polarized light (Picture 4). Given that Congo red staining with prior potassium permanganate incubation was negative, we diagnosed her with amyloid A (AA) amyloidosis of the ascending colon. AA amyloidosis is sometimes associated with rheumatoid arthritis but rarely with $\operatorname{SLE}(1,2)$. In this case, the long history of SLE may have contributed to the development of AA amyloidosis.

The authors state that they have no Conflict of Interest (COI).

\section{References}

1. Düzgün N. Amyloid A amyloidosis and systemic lupus erythematosus. Expert Rev Clin Immunol 3: 701-708, 2007.

2. Gomez-Puerta JA, Cervera R, Moll C, et al. Proliferative lupus nephritis in a patient with systemic lupus erythematosus and longstanding secondary amyloid nephropathy. Clin Rheumatol 28: 9597, 2009.

The Internal Medicine is an Open Access journal distributed under the Creative Commons Attribution-NonCommercial-NoDerivatives 4.0 International License. To view the details of this license, please visit (https://creativecommons.org/licenses/ by-nc-nd/4.0/).

(C) 2020 The Japanese Society of Internal Medicine Intern Med 59: 2799-2800, 2020 